История логики

History of Logic

S. GARIN

\title{
Minimal Categorical System and Predication Theory In Porphyry
}

\author{
Garin Sergei \\ Kuban State University \\ 149 Stavropolskaya St., Krasnodar, 350040, Russian Federation \\ E-mail: svgarin@gmail.com
}

The article considers some problematic aspects of Porphyry's typology of Aristotle's categories and the theory of predication. Minimal ( $\left.\dot{\varepsilon} \lambda \alpha \chi^{i} \sigma \tau \varsigma^{\prime}\right)$ class of categories in Porphyry is revealed. The work has shed some light on the opposition between

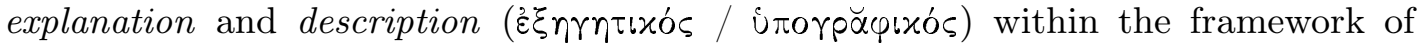
ancient categorical logic. A fourfold pattern of predication theory in Porphyry is described. The study aims to illuminate the development of Porphyry's predication theory towards the archaic doctrine of quantifiers. Particular attention is paid to Porphyry's account of semantic relation between sets. The paper represents Porphyry's nine kinds of class / item relationships. The article focuses on the awakening of academic interest to the logical heritage of Porphyry.

Keywords: history of logic, categories, predication, Porphyry, Aristotle

If Aristotle's theory of language and logic became the steady subject of intense study and scholarly interest of many researchers $[1,6,7,9]$, the same cannot be said about the work of the outstanding logician and philosopher, Porphyry of Tyre. Key works of Porphyry have come to the attention of scholars only in the XX century [2]. A relatively complete edition of the fragments of the Tyrian author was published only in 1993 [8]. The main scholarly interest related to Porphyry is connected either with his attitude to the heritage of Plotinus [4] and in a broad sense, to the Neo-Platonic tradition, or with his critical position towards Christianity. And in both cases, these studies are beyond the scope

(C) Garin S. 
of logic. Some significant tractates of Porphyry (e.g. so-called "minor" commentary $^{1}$, having a Socratic question and answer form) have not yet been translated to Russian, and Porphyry's logical doctrine beyond his "Eı $\sigma \gamma \omega \gamma n$ " has not received sufficient attention in the logical writings of Russian scholars. However, as we think, Porphyry - is one of the overt architects of ancient logic and semantics, the author, who predetermined the subsequent vectors of development of these sciences for centuries.

In this article we will take into consideration some aspects of Porphyry's categorical doctrine and theory of predication in his commentary approach to Aristotle's logic. The ideas of Porphyry, as discussed in this article, undoubtedly have origins in the logic of Aristotle. However, where we have only a cursory mention and sketch ideas in Aristotle, in Porphyry we see a detailed logical argument.

The key to Porphyry's logical tractates are undoubtedly his "Commentaries" on the "Categories" of Aristotle. We know at least several of his treatises dedicated to this subject; the only extant to us, in addition to the "Eı $\sigma \alpha \gamma \omega \gamma$ '" is the so-called "minor" commentary, having a question and answer form.

In his minor commentary on the "Categories" [3], Porphyry, explaining logical and semantic aspects of the interpretation of general terms, expounds that in addition to the traditional division into ten types

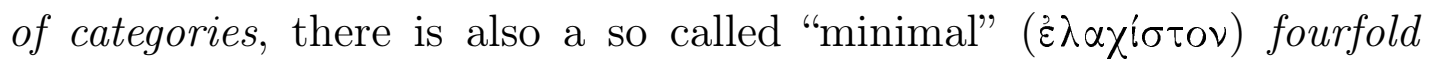
division:

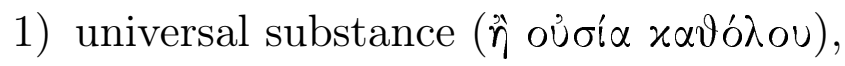

2) particular substance (

3) universal accident ( پ̀ $\sigma u \mu \beta \varepsilon \beta \eta x o ́ \tau \alpha ~ \varkappa \alpha \vartheta o ́ \lambda o u)$,

4) particular accident (

This division, due to its generality, has a descriptive rather than definitive character. It is noteworthy that Porphyry's expression here does not contain the term "category" for the description of these four reduced terms of so-called ontological square:

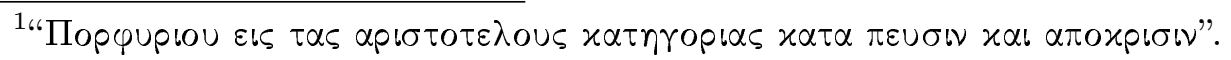




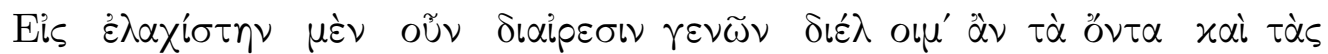

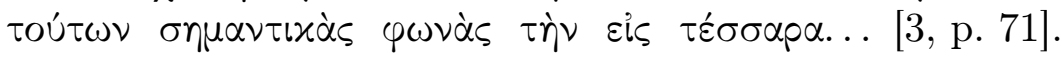

The smallest number of classes into which I could divide beings and the words that signify them is four...

(Here and after English translation is by S. K. Strange).

Instead of "categories", we see an extremely important Porphyry concept

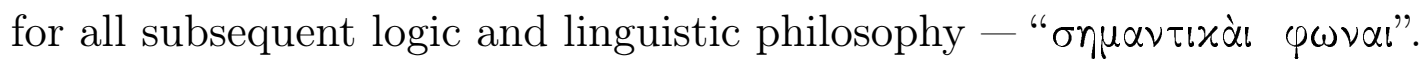

Following Aristotle, Porphyry thinks logically: if categories cannot be defined in terms of a higher generic level, "for there can be no higher genus above substance or accident", the definitive logic does not appear to be applicable to them. As a consequence, instead of definitive concepts, the theory involves so-called hyphographical (iđorpăфıxós), i.e. descriptive means. This aspect had raised a significant number of difficulties in the commentary tradition, which has been reflected in a special question of Porphyry's tractate. In response, Porphyry contrasts the definitive, or, literally speaking, exegetical interpretation to descriptive, hyphographical:

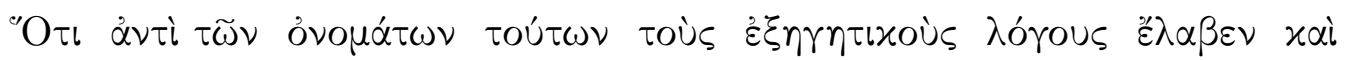

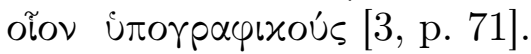

Because he used instead the accounts that serve to explain these terms, that is, their descriptive accounts.

It is noteworthy that other authors also share the opposition

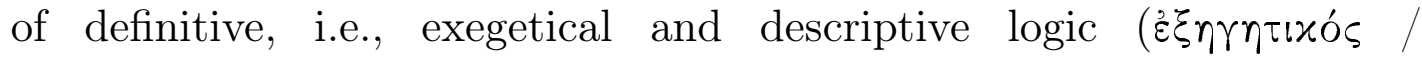
iлorpăфixós), commenting on the "Categories". For example, Simplicius [5], tackling the question of the nature of homonyms,

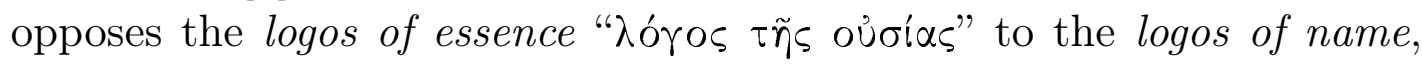
i.e., definitive and descriptive accounts. According to Simplicius, objects can be linguistically reflected in both nominal and conceptual function; the latter, in its turn, can be descriptive or definitive. We see in

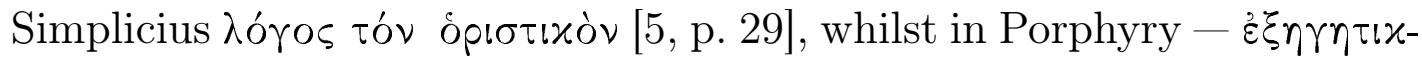
ós. Hyphographical logos, being the description, which allows us to explain features of generic terms, including the highest gender and other problematic objects - individuals. On the contrary, the explanation, in 
accordance with this approach, has a definitive function - it logically determines generic and specific characteristics of the object.

In looking at ways of defending the minimal division of categories, Porphyry indicates that it is possible to provide an even simpler version, consisting only of two parameters - the substance and the accident:

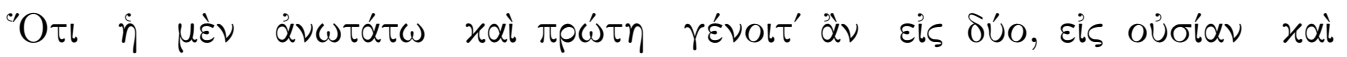
$\sigma \cup \mu \beta \varepsilon \beta \eta x o ́ s ~[3$, p. 71]

Because the first and highest division is into two, namely substance and accident.

However, as Porphyry says, substances and accidents cannot be conveyed without expressing them as either universal or particular. Porphyry thinks that simple substances don't exist. Similarly, we know that there are no simple objects outside the facts in early Wittgenstein's ontology. Substances, according to Porphyry, are given either universally, at the level of general terms (logical objects), or individually, at the level of physical objects, therefore, the fourfold division is the most minimal one.

Porphyry transforms these categories into the already mentioned

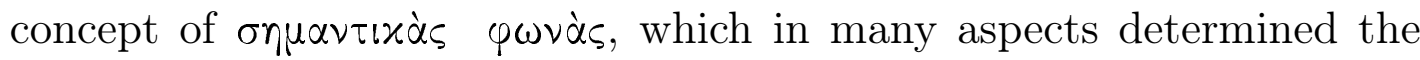
subsequent motion of logic from ontology towards the theory of meaning and predication.

The next block of Porphyry's arguments deals with the ontological compatibility of semantic categorical components - substance and accidental (attribute). Porphyry explains the ontological differentiation:

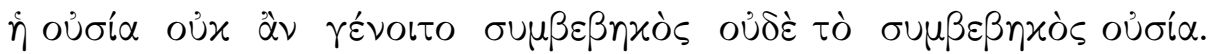

A substance cannot come to be an accident nor an accident a substance.

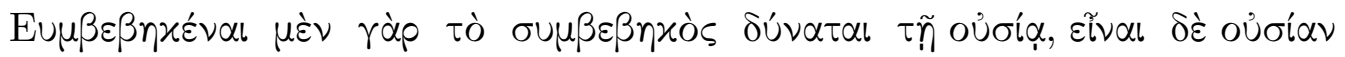

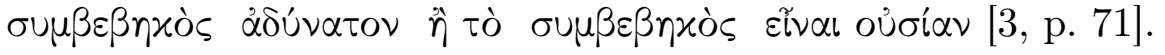

For an accident can be an accident of a substance, but a substance cannot be an accident nor can an accident be a substance.

Thus, we get a conclusion that an accident can only exist in the substance, and as we consider accidental as such, it is not a substance. 
Porphyry clarifies the specified Aristotelian thesis with the following argument: white is an accidental attribute of the body, when we say, "the body is white". But "white" and "body" per se are not the same thing, "but the white qua white is not the same as body" [3, p. 73] (in connection with this aspect, the issue of iteration of accidental this white as accidental attribute of white, raised in the recent logical literature).

Ontology and semantics of universals in Porphyry are connected with the thesis that universal may not be a part of the individual $-\tilde{n}$

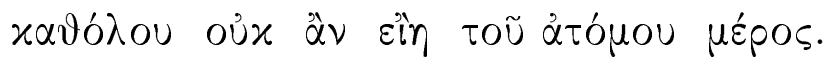

In explaining semantic aspects of Aristotle's logic in a new "descriptive" framework, Porphyry develops categorical typology. As Porphyry suggests, in Aristotle's logic, the object can act in the following modifications:

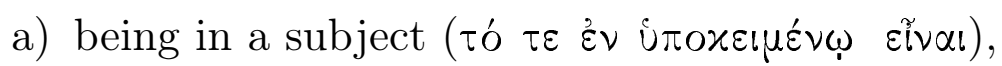

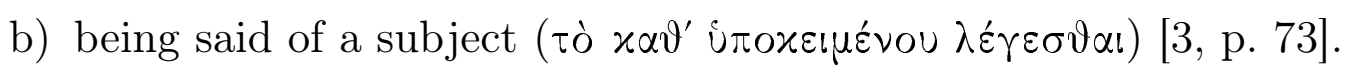

Next Porphyry forms its negative modifications:

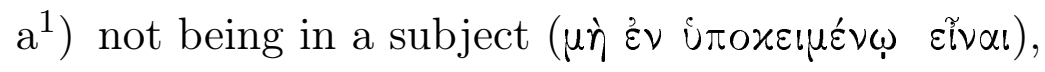

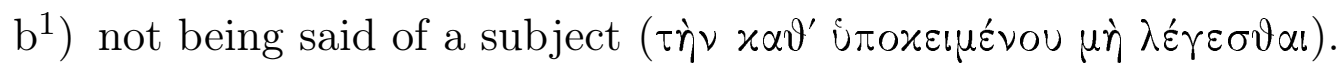

Porphyry applies these four kinds to the pure, unmixed types of division.

One of the darkest aspects in Aristotle's "Categories" is probably the doctrine of logical, semantic and ontological location of accident in its relation to the substance, and grammatically speaking - to the subject of statement. As it was aforementioned, according to Aristotle, accidental cannot be the subject. With regard to accidental as such, which is not the subject, Porphyry writes the following:

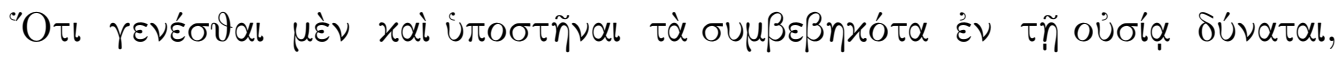

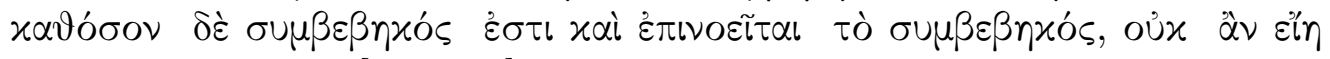

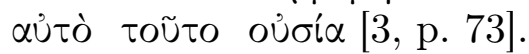


Because accidents can come to be in substance and exist in substance, but insofar as they are accidents and are conceived as such, they cannot be substance.

Porphyry constructs analogy, according to which the expressions

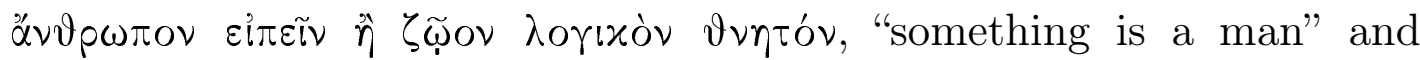
"something is a mortal rational animal" are semantically identical as well as the expressions "accident" and "being in a subject". According

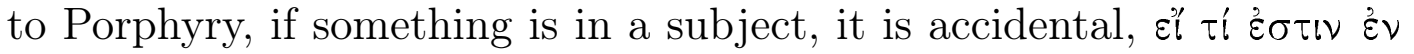

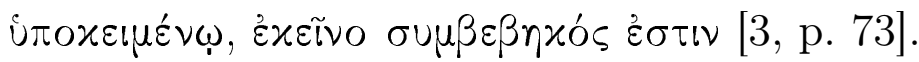

It is notorious that the Aristotelian concept of subject

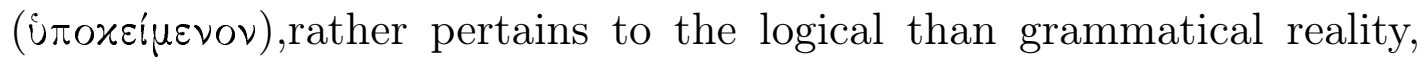
although in some cases, it may be interpreted in grammatical terms. This duality of the subject was reflected in the commentary tradition on the "Categories". The modern Russian-speaking reader, opening the "Categories", "Eı $\sigma \gamma \omega \gamma \eta$ " and Porphyry's "Commentary", and encountering the term "subject", will probably be only looking for a grammatical meaning of the word. As it is indicated in modern Russian,the concept of "subject" has lost all the extra-grammatical meanings of objects' spatial localization.

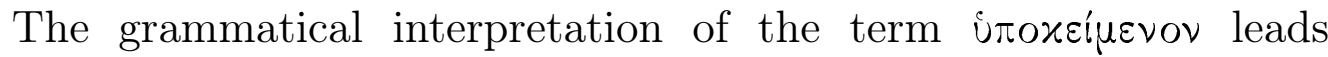
to serious inconsistencies and difficulties in explaining not only the "Categories", but also the all-subsequent ancient, especially Neoplatonic logic. The English translation of Aristotle's term as the "subject" considerably simplifies matters, because it stores the original polysemy

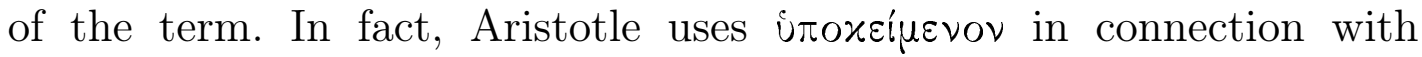
the hierarchical arrangement of objects "under" and "over". What we understand by this is not only the spatial distribution of physical objects but also a logical hierarchy of entities and attributes.

It is necessary to distinguish between grammatical, ontological and logical fore shortenings of the term i Aristotle's logic is a "container", a substratum of qualities and attributes of the object. It has an ontological, rather than linguistic projection, as the concept of the predicate, which must be distinguished from the modern grammatical term. The Aristotelian predicate, to some extent, 
does not coincide with the class of predicates of sentences, and rather is some semantic expression towards being.

The difficulty in this case is that, as Porphyry writes:

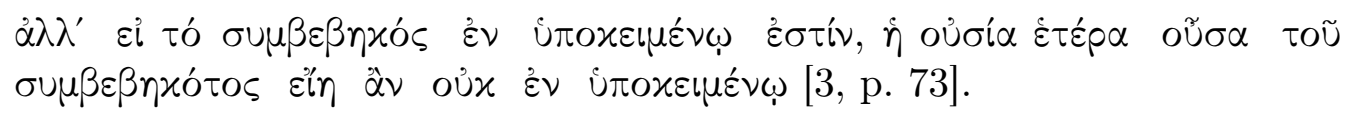

But if an accident is something that is in a subject, substance, since it is something different from accident, will not be in a subject.

However, the question that may be raised here is how the properties of a substance can be linguistically expressed (in language)? The answer is obvious - to place substance to the position of the subject (namely in the subject) and ascribe the attributes placed in the predicate.

Porphyry here develops the doctrine of the definitive location of the substance $(\dot{\eta}$ oủoí $\alpha)$

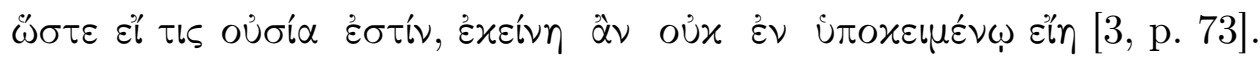

Hence if something is a substance, it is not in a subject.

It is interesting that Aristotle and Porphyry here invent the method and the topology of the semantic presence of oủoía.

Furthermore, in developing the doctrine of predication towards the archaic doctrine of quantifiers, Porphyry adds that if something is universal, it is necessarily said of a subject. Thus, if an individual has a property "to be universal", it is a predicate. This characteristic has a negative modification - if something pertains to the particular, it is not said of a subject and therefore it doesn't belong to the class of predicates. Thus, Porphyry says that we have four possible combinations

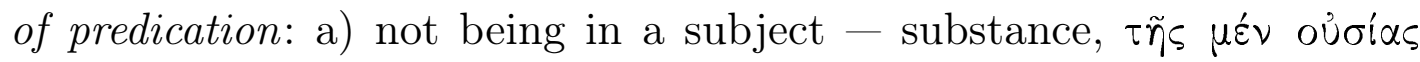

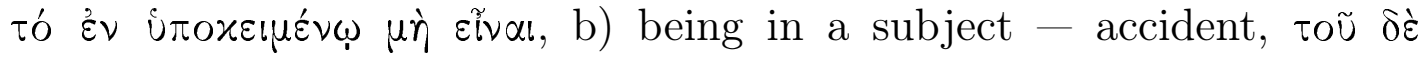

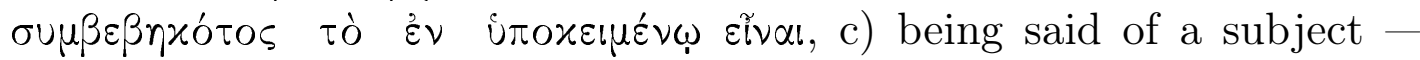

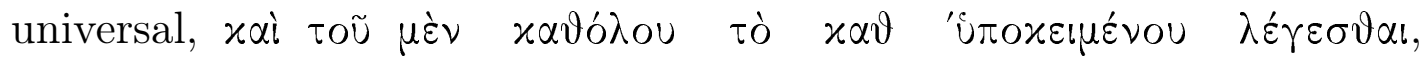

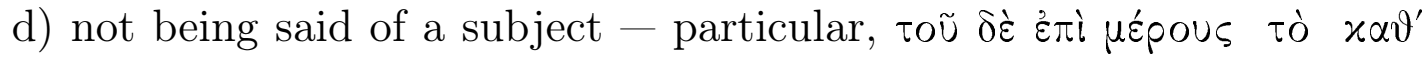

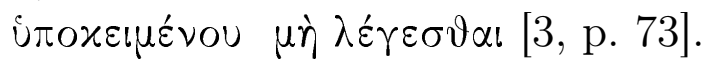

Combining in turn all the parameters examined above, Porphyry raises the question: how it is possible to define, for example, the universal 
substance in the fourfold matrix of predication? In response, he points out that universal substance is characterized by having the following:

a) predicative function,

b) logical topos outside the subject.

Actually Porphyry sets the two arguments for the characteristic function of "universal substance". The predicative function of universal substance comprises the trivial feature that it can act as a predicate and as a result, can be said of a subject. The logical topos of universal substance is conveyed by the fact that it is a substance and located outside the logical subject. Further, within the four-dimensional system of predication, Porphyry sets the parameters for universal accident. He indicates that universal accidental attribute can be described as what is said of a subject (since it is universal), and also that, being accidental, is in a subject. Thus, a universal as discussed above, has a predicative function.

Another aspect relates to the fact that universal, placed in the predicate area is necessarily logically wider than what is ascribed to it in the subject. Here Porphyry, following Aristotle, essentially uses the traditional logical concept of universal affirmative propositions, without taking into account their special subclass of general emit statements, having the predicate, which is not logically wider than the subject, and, as a consequence, the proposition is not distributed.

Continuing the four-dimensional logical theory of predication, Porphyry raises the question about the characteristics of the individual substance within the scopes of this system. In Porphyry's logic, individual substance is determined by the two negative parameters: "not being said of a subject and not being in a subject" [3, p. 73]. If something is not universal, but particular, it can't be said of a subject, but as far as it is a substance and not accident, it cannot be in a subject.

Then the question arises, how to describe a particular accidental

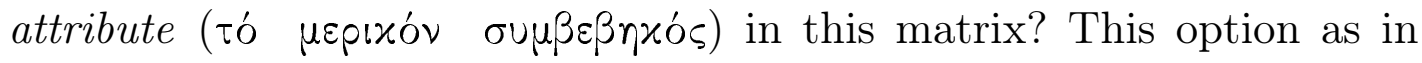
the case considered above, is determined by the twofold function. So, since there is something particular, it cannot be said of a subject, and as far as it is accidental, it can be only in a subject. Thus, we see that 
Porphyry describes these logical-categorical aspects within two options predicative and topological.

However, careful analysis of these categories obviously shows that there are a number of difficulties in this theory, which Porphyry foresaw and brought in the special topics of the commentary. In particular, the question arises, what is the denotata of the expression "items are said of a subject, but are not in a subject?" Porphyry goes here from the predicate function to the set of individuals, responding that the answer is "class of universal substances". Answering the question of the disciple, Porphyry constructs a twofold matrix of predication and logical topos: if it is universal - it is a predicate, i.e., said of a subject, and at the same time - a substance that is not in a subject.

However, another question arises: why is the inhesion of the universal attribute to an object denoted by the predicative function "said of", whereas accidental attribute - through the verbal function "is"? Porphyry puts forward the problem specifically:

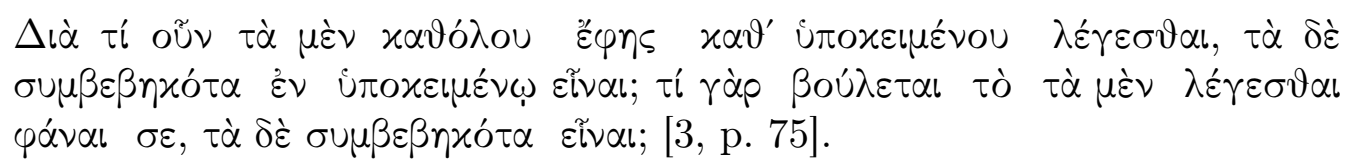

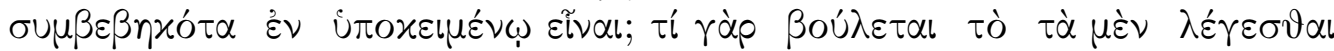

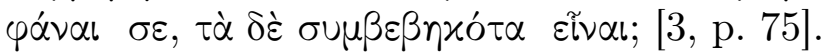

Why did you say that universals are said of a subject, but that accidents are in a subject? What do you mean by speaking of the former as 'said of, but of accidents as "being"?

Porphyry's answer is interesting because it moves away from the direct interpretation of the ontological aspects of categories, referring to the fact that these issues are "too profound" and beyond the capacities of the beginner's mind, as well as in "Eı $\sigma \alpha \omega \gamma \eta$ " (1,13-14) Porphyry refuses from the discussion of the ontological status of universal substances.

Considering the peculiarity of predication, namely the criteria of a predicate's inhesion to a subject, Porphyry, actually develops a doctrine of semantic relation between sets. Answering the question "Пó $\alpha \alpha$ oũv

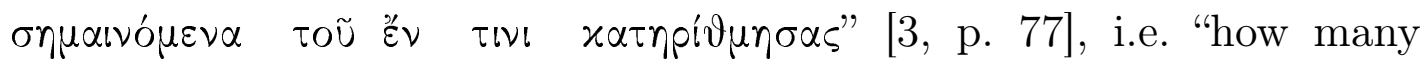
significations of 'being in something' do you count?" Porphyry indicates nine kinds of relationships between classes. 


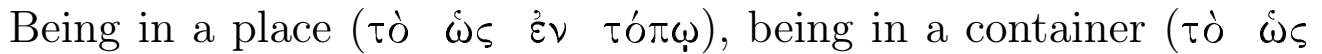

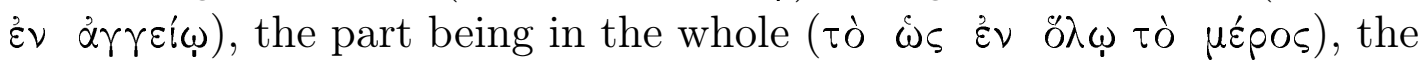

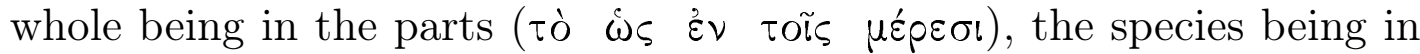

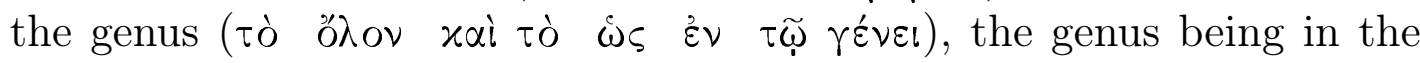

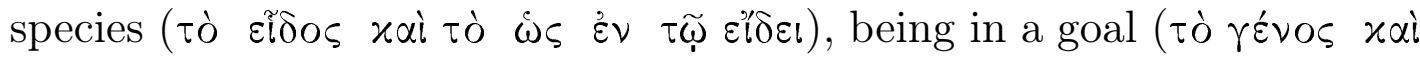

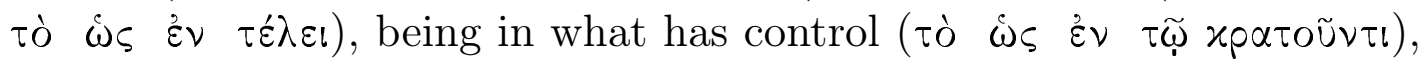

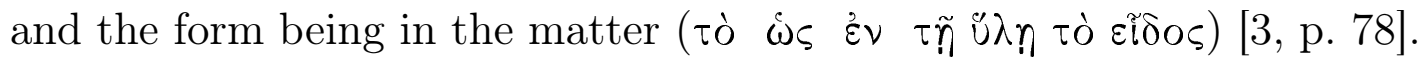
Thus, the relationship between the terms of an affirmative proposition in Porphyry's theory of predication may pertain to one of these nine types. It should be noted that Aristotle distinguished only two of these nine types of relations, namely, the relation of the part being in the whole, and being in a place that contains, in spite of the commentator nature of Porphyry's thought, a very significant innovative component.

Porphyry develops his doctrine of predication, not only in terms of the relationship between sets, but also in the context of different predicate frameworks. Firstly, predication, according to Porphyry, can act as the nominal function, and secondly, in object-denotative function. There is also a third combined way - both in nominal, and denotative functions.Here we have a pre-Fregean sketchy attempt to build a theory of intentional (denotative-designative) features of language. Porphyry considers here a synthetic type of predication, when denotative and nominal components equally relate to the subject of proposition.In this case, if something is predicated to the subject, both nominal and denotative functions are inherent to the subject.

These aspects of the Porphyry's logic, in our opinion, require a separate comprehensive study.

\section{References}

[1] Back, A. Aristotle's theory of predication. London: Brill, 2000. 347 pp.

[2] Bidez, J. Vie de Porphyre. Gent: OlmsVerlag, 1913. 166 pp.

[3] Busse, A. Commentaria in Aristotelem Graeca. Vol. 4.1. Berlin: Reimer, 1887. 183 pp.

[4] Johnson, A. P. Religion And Identity In Porphyry Of Tyre. The Limits Of Hellenism In Late Antiquity. Cambridge: Cambridge University Press, 2013. 374 pp. 
[5] Kalbfleisch, K. Commentaria in Aristotelem Graeca. Vol. 8. Berlin: Reimer, 1907. 575 pp.

[6] Malink, M. Aristotle's Modal Syllogistic. Harvard: Harvard University Press, 2013. 366 pp.

[7] Rijk, L. M. Aristotle: Semantics and Ontology. Koln: Brill, 2002. 500 pp.

[8] Smith, A. Porphyrii Philosophi Fragmenta. Leipzig: Teubner, 1993. $654 \mathrm{pp}$.

[9] Woods, J. Aristotle's Earlier Logic. Milton Keynes: College Publications, 2014. 274 pp. 